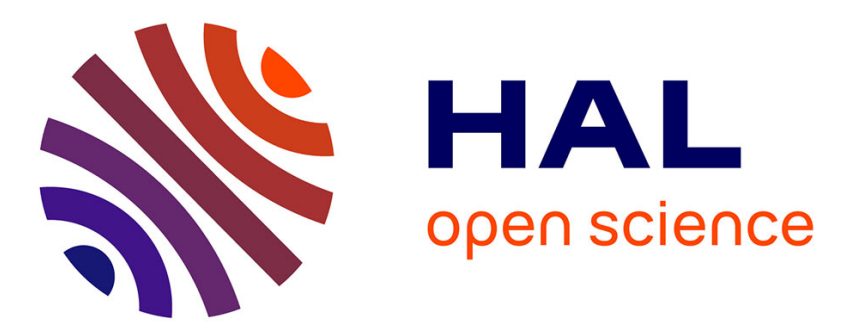

\title{
Les donations du roi Lālibalā: éléments pour une géographie du royaume chrétien d'Éthiopie au tournant du XIIe et du XIIIe siècle
}

\author{
Marie-Laure Derat
}

\section{- To cite this version:}

Marie-Laure Derat. Les donations du roi Lālibalā: éléments pour une géographie du royaume chrétien d'Éthiopie au tournant du XIIe et du XIIIe siècle. Annales d'Éthiopie, 2010, 25 (1), pp.19-42. 10.3406/ethio.2010.1405 . halshs-02552666

\section{HAL Id: halshs-02552666 \\ https://shs.hal.science/halshs-02552666}

Submitted on 23 Apr 2020

HAL is a multi-disciplinary open access archive for the deposit and dissemination of scientific research documents, whether they are published or not. The documents may come from teaching and research institutions in France or abroad, or from public or private research centers.
L'archive ouverte pluridisciplinaire HAL, est destinée au dépôt et à la diffusion de documents scientifiques de niveau recherche, publiés ou non, émanant des établissements d'enseignement et de recherche français ou étrangers, des laboratoires publics ou privés. 
Les donations du roi Lālibalā : éléments pour une géographie du royaume chrétien d'Éthiopie au tournant du XIle et du XIIle siècle Marie-Laure Derat

\section{Citer ce document / Cite this document :}

Derat Marie-Laure. Les donations du roi Lālibalā : éléments pour une géographie du royaume chrétien d'Éthiopie au tournant du XIle et du XIIle siècle. In: Annales d'Ethiopie. Volume 25, année 2010. pp. 19-42;

doi : 10.3406/ethio.2010.1405

http://www.persee.fr/doc/ethio_0066-2127_2010_num_25_1_1405

Document généré le 08/03/2018 


\begin{abstract}
The donations of King Lālibalā : elements for a geography of the Ethiopian Christian Kingdom at the turn of the 13th centuries - The written documentation on king Lālibalā, produced in the kingdom of Ethiopia when this king was reigning, is composed of three land grants, up to now objects of little scientific interest : the land donation recorded in the gospel preserved in Bêta Medhānē 'Alam (Lālibalā) and the two charters of the "Golden Gospel" of Dabra Libānos of Šemazānā. The purpose of this article is to give a new edition of these three texts, with a translation. This work is based on the study of the photographs of the Dabra Libānos gospels taken by Roger Schneider and now available in the Walda Masqal Centre, a department of the Institute of Ethiopian Studies, which preserves the archives of Roger Schneider. The geographical information transmitted by those texts will then be discussed in order to sort out the questions of the kingdom's territory and its management, its extension and its centre.
\end{abstract}

\title{
Résumé
}

La documentation écrite concernant le roi Lālibalā, contemporaine de son règne et produite dans le royaume d'Éthiopie, consiste en trois donations de terre, fort peu étudiées jusqu'ici : la donation inscrite dans l'évangéliaire conservé à Bēta Medhānē 'Alam à Lālibalā et les deux chartes de «l'Évangile d'or » de Dabra Libānos du Šemazānā. Le propos de cet article est de donner une nouvelle édition de ces textes, accompagnées d'une traduction. Cela est possible suite à l'apport considérable des photographies de cet Évangile réalisées par Roger Schneider et conservées aujourd'hui dans une dépendance de l'Institute of Ethiopian Studies, le centre Walda Masqal à Addis Ababa, qui conserve les archives Roger Schneider. Puis une discussion sera ouverte concernant les informations géographiques transmises par ces textes, afin de considérer d'un œil neuf la question de la gestion du territoire du royaume par le roi zāgwē, l'extension de celui-ci et son centre. 


\title{
Les donations du roi Lālibalā Éléments pour une géographie du royaume chrétien d'Éthiopie au tournant du XII et du XIII siècle
}

\author{
Marie-Laure Derat ${ }^{*}$
}

La documentation écrite concernant le roi Lālibalā, produite dans le royaume d'Éthiopie durant le règne de ce souverain, a été très peu étudiée. Elle consiste en trois textes de nature identique. Il s'agit de donations accordées par le roi à des églises avec lesquelles il entretenait un lien particulier. Deux de ces documents ont été édités au début du XX $\mathrm{XX}^{\mathrm{e}}$ siècle par Carlo Conti Rossini. Celui-ci a en effet publié les textes ge'ez copiés sur les folios vierges d'un évangéliaire conservé dans l'église de Dabra Libānos de 'Ahām dans le Šemazānāî'. Parmi eux figurent deux donations du roi Lālibalā (ce sont les actes $n^{\circ} 6$ et $n^{\circ} 7$ de l'édition de Carlo Conti Rossini, chacun étant divisés en deux parties ${ }^{2}$ ), la première en faveur de l'église de Marie et de l'église de la Croix, la seconde pour l'église de Mațțāe de 'Ahām. Carlo Conti Rossini n'a pas traduit les documents mais a fourni un commentaire savant pour chacun d'eux, qui reste la référence de tous les auteurs et qui a été très peu dépassé depuis. Le troisième texte est en revanche inédit. Il est conservé dans l'évangéliaire de l'église de Bēta Madhuānē 'Alam à Lālibalā, microfilmé par le projet EMML et connu par la cote EMML 6907 (non catalogué). La donation est en partie illisible, le folio sur lequel elle a été copiée étant rogné et très endommagé par l'humidité. Toutefois, les dernières lignes du texte sont lisibles et permettent de savoir que cette donation du roi Lālibalā fut faite en faveur de l'église de Bēta Madhānēe 'Alam à Lālibalā.

Le propos de cet article est de donner une nouvelle édition de ces textes accompagnée d'une traduction, mais aussi de discuter des informations

\footnotetext{
* Centre Français des Études Éthiopiennes (USR 3137/UMIFRE 23), CNRS \& Ministère des Affaires Étrangères, Addis Abeba, Éthiopie.

1 Conti Rossini, 1901. Une brève analyse des possessions foncières de Dabra Libānos figure dans Conti Rossini, 1916.

2 Pour plus de clarté, la numérotation adoptée par Carlo Conti Rossini est reprise ici.
} 


\section{Marie-Laure Derat}

géographiques qu'ils transmettent pour poser la question de la gestion du territoire du royaume par le roi Lālibalā, de l'extension de ce royaume et de son centre.

Plusieurs circonstances sont à l'origine de cette initiative. Au cours de l'année 2010, des travaux menés dans les archives Roger Schneider ${ }^{3}$ ont permis d'étudier les photographies que celui-ci avait prises de l'évangéliaire de Dabra Libānos en 1975. Ces photographies sont d'une valeur inestimable, dans la mesure où elles livrent à la fois des images de la couverture dorée du manuscrit où se trouve une inscription que Carlo Conti Rossini avait notée, mais aussi des images des donations royales dont celles de Lālibalā, permettant ainsi de contrôler et corriger l'édition réalisée en 1901 par Carlo Conti Rossini. Il semble que Roger Schneider, en collaboration avec Merid Wolde Aregay, préparait une nouvelle étude des donations de l'évangéliaire de Dabra Libānos, à commencer par une édition critique et une traduction ${ }^{4}$. Mais ce travail n'a jamais été achevé.

Il faut ici signaler qu'en 1993 et 1994, Alessandro Bausi a pu revoir l'évangéliaire de Dabra Libānos et le prendre en photo. L'une d'elle, qui concerne la première partie de l'acte $\mathrm{n}^{07}$ (1 ${ }^{\mathrm{er}}$ fascicule) a été publiée dans l'article de l'Encyclopaedia Aethiopica consacré à Dabra Libānos du Šemazānā $\overline{5}^{5}$. Pour le reste, il annonce une édition complète de tous les actes de donations de l'Évangile ${ }^{6}$ et a d'ores et déjà fourni un index des toponymes figurant dans les actes ${ }^{7}$.

Par ailleurs, en 2008, Ewa Balicka Witakowska eut l'obligeance de me fournir les photographies d'un manuscrit provenant de l'église d'Urā Masqal'. Il s'agit d'un recueil de donations du roi Țanțawedem, dont le nom de règne était Salomon, pour l'église de Qefereyā à 'Urā Masqal'. Țanțawedem, dont le règne est difficile à situer

3 À la mort de Roger Schneider (1917-2002), sa famille fit don de ses archives et de sa bibliothèque à l'Institute of Ethiopian Studies (IES). L'ensemble est aujourd'hui conservé au centre Walda Masqal à Addis Abeba, annexe de l'IES pour tout ce qui concerne les dépots archivistiques. Au cours de l'année 2010, suite à une convention avec l'IES et sous les auspices du Centre Français des Études Éthiopiennes, j’ai réalisé un inventaire complet du fond, les ouvrages, revues et archives ont été classées. Les archives elles-mêmes ont été numérisées afin de les sauvegarder.

4 Cette information se trouve dans une copie d'une lettre typographiée envoyée à Claude Lepage en juin 1994. Dans cette lettre, Roger Schneider expose ce qu'il souhaite faire et ses hypothèses sur la datation du manuscrit, sur lesquelles nous reviendrons plus loin.

5 Bausi, $2005: 28$. Il s'agit de la copie du deuxième fascicule fol. $7 \mathrm{v}$.

6 Bausi, 2007 : 82. Il n'est pas question ici de prendre date avant la publication d'Alessandro Bausi. Le projet est tout autre : il s'agit de rassembler le corpus des textes produits par l'administration zag'wè. Il se trouve que deux des trois documents émanant du roi Lālibalā sont conservés dans l'Évangile de Dabra Libānos et que pour progresser dans la connaissance historique de la période zāgōè, il est indispensable de se fonder sur ces textes.

7 Bausi, 2007.

8 Je tiens à la remercier chaleureusement pour ce don et en général pour sa politique de partage des données via la base de données - Mezgeba Se'elāt - qu'elle alimente avec Michael Gervers. Le recueil des donations du roi Țanțawedem peut être consulté en ligne: Margaba séelät (http://ethiopia.deeds.utoronto.ca; username: guest; password: deeds), cl. Michael Gervers, MG$2005.092: 012-023$.

9 Ce recueil avait déjà été signalé par P. Henze (2007: 158-159) qui indiquait qu'il avait confié les photographies du manuscrit à Getatchew Haile. Je me suis rendue à 'Urā Masqal en mars 2009 afin de consulter la bibliothèque de l'église et re-photographier le manuscrit en question. 
(fin $\mathrm{XI}^{\mathrm{e}}-\mathrm{XII}^{\mathrm{e}}$ siècle ?) ${ }^{10}$, était un prédécesseur du roi Lālibalā. La comparaison des donations de Tanțawedem avec celles de Lālibalā a permis de résoudre une difficulté de l'acte $n^{\circ} 6$ de l'évangéliaire de Dabra Libānos et de proposer une traduction plus claire à un passage jusque-là difficile à comprendre.

Les traductions qui figurent dans cet article sont à la fois le fruit d'un travail personnel et collectif. Ces deux dernières années, en effet, avec Claire Bosc-Tiessé, Emmanuel Fritsch et Daniel Assefa nous avons monté un groupe de travail afin d'examiner ensemble les difficultés posées par quelques textes ge'ez. À certaines occasions, Manfred Kropp et Anaïs Wion se sont joints à ce groupe, au gré de leurs allées et venues en Éthiopie. Les donations du roi Lālibalā ont fait l'objet de nos examens minutieux. Il reste pourtant des zones d'ombre et des imperfections dont la responsabilité me revient entièrement.

Outre que ces documents sont des sources inestimables pour l'histoire du royaume d'Éthiopie au tournant des XII et XIII siècles, ils donnent également des informations concernant l'extension géographique du pouvoir de Lālibalā et permettent de mieux positionner le site de Lālibalā par rapport au reste du royaume.

\section{Donation du roi Lālibalā dans l'Évangile de Bēta Madhānēe 'Alam}

Le premier document est une donation du roi Lālibalā en faveur de l'église de Bēta Madhānē 'Alam. Il est conservé dans un Évangile désormais exposé dans le musée de l'église de Lālibalā qui se trouve dans les nouveaux bâtiments construits par l'Union européenne à l'entrée du site. Cet évangéliaire est bien connu pour son folio trilingue - copte, arabe, ge'ez - publié par Augusto Monti della Corte ${ }^{11}$ et dont la traduction arabe a été revue par Madeleine Schneider ${ }^{12}$. Ce folio contient des donations du roi Dāwit pour l'église de Bētalehẹem ${ }^{13}$ ainsi qu'une donation du roi Lebna Dengel à un individu, Sāf Sagad, pour la célébration de la commémoration de son père Wasan Sagad. Il compte de nombreux autres actes qui montrent la permanence dans le temps de l'emploi de ce manuscrit comme conservatoire d'archives ${ }^{14}$.

L'avant-dernier folio du manuscrit (fol. 208), qui correspond à la fin de l'Évangile de Jean, présente à la fois, au recto, un colophon - en grande partie illisible - et au verso, une donation de terres du roi Lālibalā, dont la majeure partie manque, et qui a fait l'objet de corrections par des copistes. Ce folio a été examiné par Siegbert Uhlig dans son étude sur la paléographie des manuscrits éthiopiens. Il considère qu'il s'agit du colophon du manuscrit et avance l'idée que celui-ci est une copie du XIII siècle d'un manuscrit du XII ${ }^{\mathrm{e}}{ }^{5}$. Par conséquent, il n'emploie pas la

\footnotetext{
10 Voir infra.

11 Monti della Corte, 1940 : 136-138.

12 Schneider, $1970: 83$.

13 Voir au sujet de cette donation Bosc-Tiessé \& Derat, 2010.

14 Idée développée dans l'article de Bosc-Tiessé \& Derat, 2010.

15 Uhlig, 1988 : 103 ; Uhlig, 1990 : 30.
} 


\section{Marie-Laure Derat}

donation de terres de Lālibalā pour dater une graphie de la fin du XII ${ }^{\mathrm{e}}$ ou du début du XIII' siècle.

Si la copie de l'Évangile de Bēta Madhānēe 'Alam est plus tardive que la donation de terre du roi Lālibalā, cela pose nécessairement la question de l'authenticité de la donation. Or l'Évangile et la donation du roi Lālibalā ne sont pas écrites de la même main, ce qui serait le cas s'il s'agissait d'une copie secondaire du manuscrit en son entier, y compris la donation. Par ailleurs, le raisonnement de Siegbert Uhlig est pour le moins curieux. Son point de départ repose sur les dates de règne du roi Lālibalā, selon lui 1140-1180. D’après les donations de terre conservées dans l'Évangile de Dabra Libānos du Šemazānā, Lālibalā régnait en l'an de grâce 1089 et en l'an de grâce 409 (dans le calendrier grégorien 1225) ${ }^{16}$. La première date est curieuse mais nous y reviendrons plus loin ${ }^{17}$. La période du règne de Lālibalā établie par ces donations de terre s'accorde avec ce que l'on sait du royaume d'Éthiopie et du roi Lālibalā par la notice consacrée au patriarche Jean VI (1189-1216) dans l'Histoire des patriarches d'Alexandrie ${ }^{18}$. Et peut-être faut-il aussi accorder quelque crédit à une note historique introduite dans certaines copies des actes de Lālibalā, mais aussi dans des manuscrits conservés dans les églises de Lālibalā, qui déclare que ce souverain commença à régner en 1185 et qu'il acheva les églises qu'il avait faites creuser en $1208{ }^{19}$. Par conséquent, une partie du règne de Lālibalā se déroule au XIII ${ }^{\text {e }}$ iècle. L'argument de Siegbert Uhlig pour une nouvelle copie du manuscrit de Bēta Madhānē 'Alam au XIII' siècle est donc infondé car tout porte à admettre que la donation du roi Lālibalā est bien l'acte authentique copié au moment où celui-ci a été promulgué, soit à la fin du XII e soit au XIII siècle.

Le folio 208 présente à la fois un colophon pour les Évangiles, au recto, et une donation du roi Lālibalā, au verso. Le colophon est écrit sur cinq lignes mais la colonne, qui compte en moyenne dix caractères dans le reste du manuscrit, est ici tronquée et seuls trois caractères (pour la première ligne) à six caractères (pour la dernière ligne) sont lisibles. Le texte débute par le mot $\boldsymbol{\top} \cdot \boldsymbol{6 . 9}[\boldsymbol{\sigma o}]$ (littéralement, il est achevé) qui semble bien signaler les débuts d'un colophon. Au verso du folio 208 figure en revanche une donation dont il manque la première colonne (tronquée en partie) et le haut de la deuxième colonne. Bien que le texte soit incomplet, avant le dernier paragraphe qui mentionne le nom du donateur et contient la formule classique interdisant toute transgression de l'acte, des bribes du texte sont lisibles. On trouve à plusieurs endroits la référence à des terres (medr) suivies de leurs noms, mais ceux-ci ne sont jamais lisibles complètement. Seules les 17 dernières lignes de la deuxième colonne peuvent être restituées.

16 Conti Rossini, 1901 : 186-191.

17 Conti Rossini (1901 : 188) propose de corriger cette date en lisant non pas 1089 mais 1209, justifiant cette correction par le fait que le métropolite Mikā'ēl fut envoyé en Éthiopie par le sultan Malik alAdil qui accède au pouvoir en 1205 et qu'il fut chassé d'Éthiopie après 1209.

18 Perruchon, 1898-1899 : 76-85 ; Khater \& Burmester, 1970 : 184-193.

19 Et. Cerulli 223 (Gadla Lälibalà), Bibliothèque Vaticane, fol. 124v ; EMML 6964 (Gadla Lälibalā, église de Bēta Giyorgis de Lālibalā), fol. 132r ; EMML 6934 (Évangile, église de Bēta Golgotā de Lālibalā), fol. $163 \mathrm{v}$. 


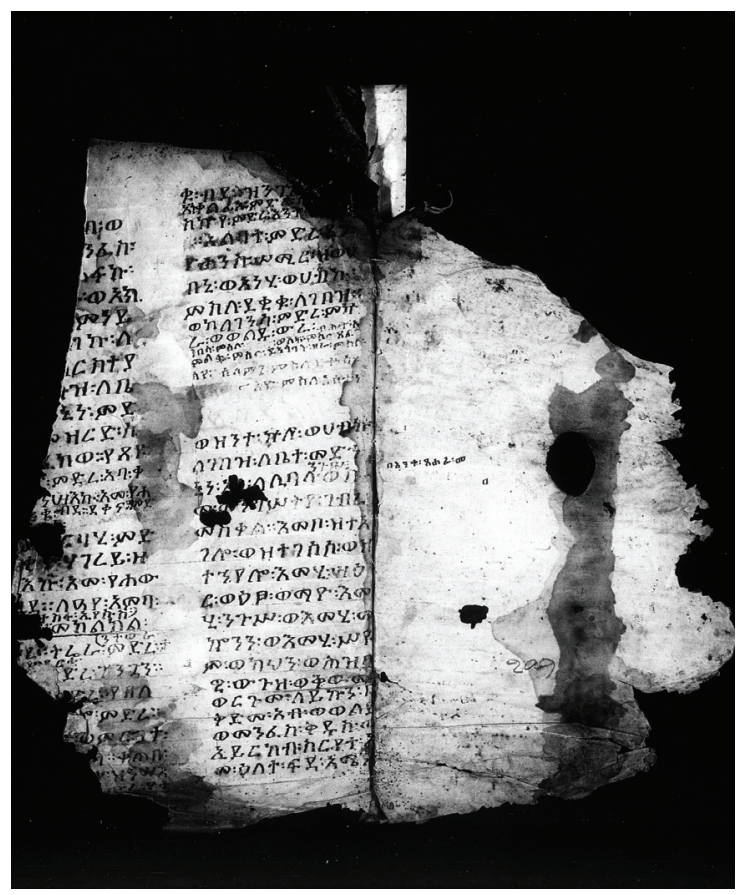

(C) EMML 6907 fol. 208v-209r

Fol. 208v : fin de la donation du roi Lālibalā

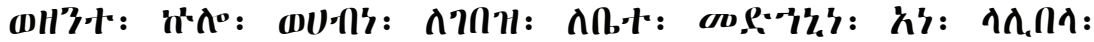

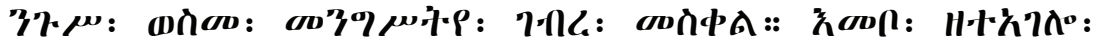

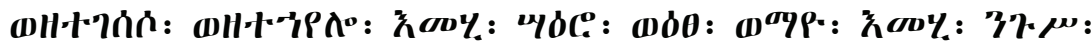

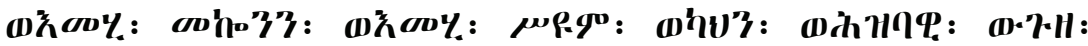

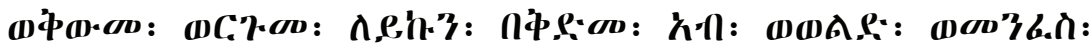

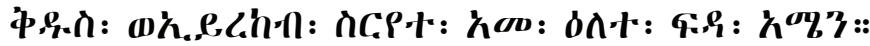

«Et j’ai donné tout cela au gabaz, l'église de notre Sauveur (Bèta Madhanina), moi, le roi Lālibalā et mon nom de règne est Gabra Masqal. Quiconque le viole ou le transgresse ou le force, que ce soit l'herbe, l'arbre ou l'eau, qu'il soit roi ou gouverneur (mak"wannen) ou chef (śeymm) ou prêtre ou du peuple, qu'il soit excommunié, exclu et maudit devant le Père, le Fils et l'Esprit Saint et qu'il ne trouve pas le pardon le jour de la récompense, amen ».

L'interprétation de la fin du texte ne pose aucun problème. L'église de Bēta Madhanina est le gabaz, c'est-à-dire la cathédrale ${ }^{20}$. On retrouve ici un terme qui désigne le plus souvent l'église d'Aksum Șeyon. Ce passage indique qu'au moment où le roi Lālibalā régnait, l'église de Bēta Madhānē 'Alam était en activité. Ce document répond par conséquent à une question que j’avais soulevée dans un

${ }^{20}$ Voir notamment Habtemichael Kidane \& Red., 2005 : 599-600. 


\section{Marie-Laure Derat}

article antérieur, à la lecture des actes de Lālibalā. Ceux-ci en effet ne citent pas nommément l'église de Bēta Madhānē 'Alam parmi celles que le roi fit creuser. Je posais alors la question de l'antériorité ou de la postériorité de ce monument par rapport aux autres ${ }^{21}$. La donation du roi Lālibalā à l'église de Madhānēe 'Alam ne permet pas d'affirmer avec certitude que le souverain est le fondateur de cette église mais on est au moins certain que celle-ci existait au tournant des XII et $\mathrm{XIII}^{\mathrm{e}}$ siècles $^{22}$. Ce document est donc particulièrement important au regard de la chronologie du site de Lālibalā. Il permet de poser une balise dans le phasage du site $^{23}$.

\section{Donations du roi Lālibalā dans l'Évangile de Dabra Libānos}

L'Évangile de Dabra Libānos est un petit manuscrit, mesurant $26 \mathrm{~cm}$ de haut pour 19,5 de large, auquel a été ajouté au début 12 folios (1 ${ }^{\text {er }}$ fascicule) au format $18 \times 16 \mathrm{~cm}$, contenant la fin d'un Gadla Qirqos dont la copie date de la fin du XVII ${ }^{e}$ siècle, et des donations de terre ${ }^{24}$. Sur les folios vierges de l'évangéliaire

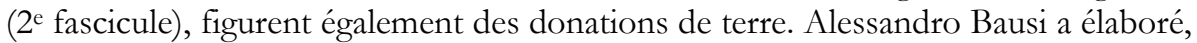
à partir des photos qu'il avait pu réaliser, une concordance entre l'édition de Carlo Conti Rossini, où les donations sont reclassées par ordre chronologique, indépendamment de leur place dans le manuscrit, et le manuscrit tel qu'il l'a vu en 1993 et 1994 et qui permet de resituer physiquement les actes dans les deux fascicules 25

Carlo Conti Rossini estimait que ce manuscrit était une copie du XVI ${ }^{\mathrm{e}}$ siècle d'un manuscrit plus ancien, de même que les donations seraient des copies secondaires d'actes authentiques. Roger Schneider a publié un bref article sur ce sujet où il estimait pour sa part que la copie de l'Évangile est antérieure au XIVe siècle et que les actes sont «en bonne partie» des originaux ${ }^{26}$. Ce qu'Alessandro Bausi confirme $^{27}$. Il y a en effet tout lieu de penser que les donations de terre figurant dans le premier fascicule sont des copies secondaires des actes figurant dans le manuscrit principal (le deuxième fascicule). Il serait intéressant de pouvoir examiner de près la reliure pour comprendre comment le premier fascicule a été adjoint au second, en maintenant la couverture ancienne.

\footnotetext{
21 Derat, 2006 : 566.

22 Au sujet de la place de Bēta Madhānē 'Alam dans le complexe de Lālibalā voir également Fritsch, 2008 :79-88; Philippson, 2009 : 174-176.

23 Sur la question du phasage, voir Fauvelle et alii, à paraître.

${ }^{24}$ Information figurant dans les notes de Roger Schneider (archives Roger Schneider, Walda Masqal Centre, Addis Abeba).

25 Bausi, 1997 [1998] : 22-23.

26 Schneider, 1989 : 163.

27 Bausi, 1997 [1998] : 15 ; Bausi, 2007 : 81.
} 
Un élément supplémentaire peut aider à dater l'Évangile de Dabra Libānos. Il s'agit de l'inscription gravée dans le métal doré qui vient recouvrir les plats de bois du manuscrit ${ }^{28}$ :

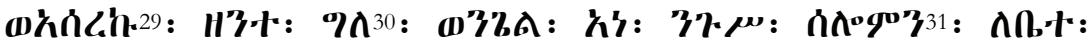

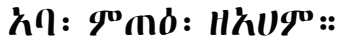

«Moi, le roi Salomon, j'ai fait relier cette couverture de l'Évangile pour

l'église d'Abbā Mețtạa'e ${ }^{32}$ de Aham ».

Roger Schneider avait posé l'hypothèse selon laquelle ce roi Salomon serait soit Yāgbe'a Șeyon (mort en 1294), soit un souverain zāgwē du XII ${ }^{e}$ siècle $^{33}$, mais sans plus de détails. Sa dernière intuition était juste ainsi que les documents préservés à 'Urā Masqal permettent de l'établir. En effet, sur une croix de procession toujours conservée à 'Urā Masqal, on trouve l'inscription suivante :

\section{H"H:

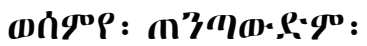

J'ai acquis cette croix (signe de la croix), moi Salomon le roi, fils de Murārā, et mon nom est Ṭanțāwedem.

De même que dans le recueil de g'elt également conservé à 'Urā Masqal, le roi Ṭanțawedem déclare que son nom de règne est Salomon et Gabra Madhen son surnom :

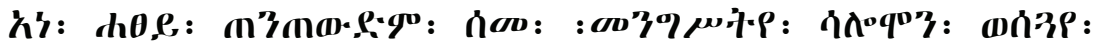

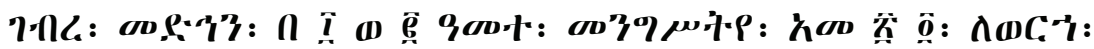
\%,P

Moi, haday Tanțawedem ${ }^{34}$, dont le nom de règne est Salomon, et mon surnom est Gabra Madhenen, dans la douzième année de mon règne, le 24 du mois de miyāasyā au lieu de Qefereyā, à l'église de la Croix ${ }^{35}$.

\footnotetext{
${ }^{28}$ Sur une face, on voit un décor effectué au repoussé (rosace au centre entourée de motifs végétaux), sur l'autre face, seule l'inscription figurant sur les pourtours a été conservée en partie tandis que le centre a été découpé. Les photographies réalisées par Roger Schneider ne permettent pas de déterminer si l'inscription est sur la couverture du manuscrit ou sur le quatrième de couverture. L'inscription a été tronquée suite au découpage si bien que toute une ligne manque. Il ne subsiste que deux lettres : $\mathbf{\Lambda}$ ou $\boldsymbol{h}$ en début de ligne et $\mathbf{W} \cdot$ en fin de ligne.

${ }^{29}$ Conti Rossini $(1901: 181)$ donne : $\boldsymbol{\omega} \boldsymbol{h} \Lambda \mathbf{h}$.

${ }^{30}$ La forme devrait être $\mathbf{9 1}$

31 inn०q०3

${ }^{32}$ Cette orthographe n'est pas courante, mais la lecture du mot ne pose pas de problème particulier. Il ne s'agit donc pas d'une faute de lecture.

33 Schneider (1989) : 163. Pour Éric Godet cette identification était déjà acquise (Godet, 1988 : 54): « Il faut rappeler que Tentawedem est le Salomon qui a offert la couverture dorée de l'Évangile d'or de Dabra Libanos de Ham ».

${ }^{34}$ On peut ici relever les différentes orthographes du nom Ṭanțawedem : tantôt Ṭanțāwedem, tantôt Tanțawedem. Dans cet article, lorsque nous ne faisons pas référence explicitement à un texte, nous avons adopté la forme Ṭanțawedem.
} 


\section{Marie-Laure Derat}

Pourquoi ce Tanțawedem serait-il notre roi Salomon? Selon toute logique, l'Évangile et sa couverture ont été donnés à Ahām avant que les premiers actes aient été inscrits sur les folios vierges du manuscrit. Comme les documents les plus anciens sont précisément ceux du roi Lālibalā, il y a tout lieu de penser que le roi Salomon était un prédécesseur de Lālibalā et non pas un successeur (dans le cas de l'identification de Salomon avec le roi Yāgbe’a Șeyon). Par conséquent, Tanțawedem est probablement le souverain qui fit don de la couverture de l'Évangile à l'église de Ahām.

Le règne de Tanțawedem est difficile à situer dans le temps. Il est le fils de Murārā/Morārā, dont on ne sait pas s'il a régné. D'après la chronologie des rois zāgwè élaborée dans les vies des saints-rois, donc tardivement, c'est le fils de son frère, Yemrehanna Krestos qui lui succède ${ }^{36}$. Ensuite, le pouvoir serait passé à Harbāy, un autre neveu de Ṭanțawedem, puis à Lālibalā, le frère d'Harbāy ${ }^{37}$. Le seul point d'ancrage chronologique est Lālibalā (?-1204-1225-?). On peut donc estimer que Tanțawedem exerça le pouvoir à la fin du XIe ou au XII e siècle. Ce qui fournit un terminus ante quem pour l'évangéliaire de Dabra Libānos : le XII siècle.

Les donations du roi Lālibalā figurant dans l'Évangile de Dabra Libānos ont été répertoriées par Carlo Conti Rossini comme étant les actes $n^{\circ} 6$ et $n^{\circ} 7$. L'acte $n^{\circ} 6$ est divisé en deux parties, totalement indépendantes l'une de l'autre. Carlo Conti Rossini ne situe pas précisément où sont copiés ces textes. Quant à Roger Schneider et Alessandro Bausi, tous deux n'ont vu que la première partie de l'acte au fol. $23 \mathrm{r}$ du deuxième fascicule mais pas la seconde partie, vraisemblablement inscrite sur un tout autre folio. Bien que physiquement distinctes, les deux parties de l'acte $n^{\circ} 6$ n'en constituent pas moins un seul et même document. Dans les deux parties, le texte précise pour qui est faite la donation: l'église de la Croix, l'église de Marie, les vierges et/ou les nonnes. Alors pourquoi le scribe n'a pas copié à la suite ces deux parties ? La réponse se trouve peut-être dans le remaniement qu'a connu le manuscrit au moins au moment où le premier fascicule a été adjoint au second. Mais selon toute logique, la suite du fol. 23r est le fol. $23 \mathrm{v}$, or au verso du folio 23, nous sommes certains qu'il n'y a pas le texte attendu puisqu'il s'agit du début de la liste des chapitres de Matthieu. Peut-être la copie de l'acte a-t-elle pris plus de place que prévu et que comme le verso du folio était déjà occupé par la liste des chapitres de Matthieu, la suite de la donation a dû être copiée sur un autre folio vierge.

Il faut noter que l'acte $n^{\circ} 6$ n'est copié qu'une seule fois, à la différence de l'acte $\mathrm{n}^{\circ} 7$ dont on dispose d'une copie dans le premier fascicule (texte $\mathrm{B}$ de

${ }^{35} G^{w}$ elt de Ṭanțawedem, église d'Urā Masqal Qefereyā, fol. 2v. Ce manuscrit est très petit $(12,8 \times 9$ $\mathrm{cm})$. Il compte 11 folios et ne possède pas de couverture. On ne peut pas dater l'écriture de la fin du

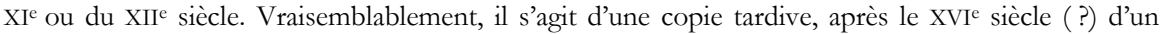
manuscrit plus ancien. Toutefois, les textes eux-mêmes paraissent avoir conservés certains aspects archaïques et, en tout cas, partagent des points communs avec les donations du roi Lālibalā préservées dans l'Évangile de Dabra Libānos.

36 Marrassini, 1995 : 64-65.

37 Perruchon, $1892: 80,108-109$. 
Conti Rossini) et d'une copie dans le second fascicule (texte A de Conti Rossini). Dans le premier fascicule, l'acte $\mathrm{n}^{\circ} 7$ se trouve au fol. 7v-9r. Roger Schneider n'a de photographies que du deuxième fascicule. D'après ses photos, les deux parties de l'acte $\mathrm{n}^{\circ} 7$ sont inscrites en continu, au fol. $7 \mathrm{v}-8 \mathrm{r}$ dans le deuxième fascicule. Toutefois, en ce qui concerne le deuxième fascicule, Alessandro Bausi n'a pas vu l'acte $\mathrm{n}^{\circ} 7$ copié en continu puisque selon sa concordance, la première partie figure au fol. $7 \mathrm{v}$ et la seconde au fol. 14r. Si l'on compare terme à terme la foliotation de Roger Schneider et celle d'Alessandro Bausi, on constate en effet que le manuscrit a été remanié entre 1975 et 1993-1994, ce qui s'explique aisément par les folios volants que l'on voit sur les photographies de Roger Schneider ${ }^{38}$.

Par conséquent, l'édition des donations du roi Lālibalā que nous proposons se fonde sur une édition corrigée par rapport à celle de Carlo Conti Rossini, ne pouvant porter que sur la première partie de l'acte $n^{\circ} 6$, et sur l'acte $n^{\circ} 7$ en son entier, mais seulement d'après la copie qu'a pu photographier Roger Schneider, c'est-à-dire celle du deuxième fascicule.

Acte ${ }^{\circ} 6$

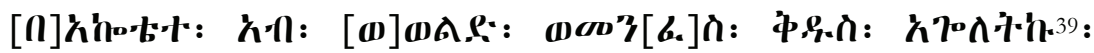

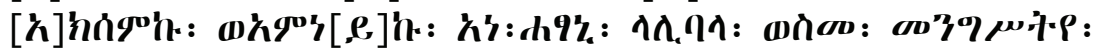

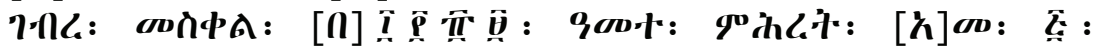

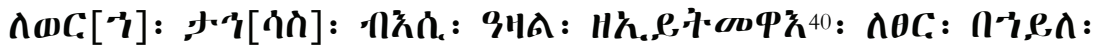

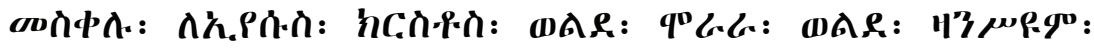

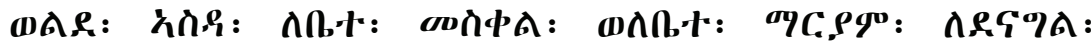

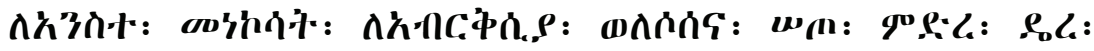

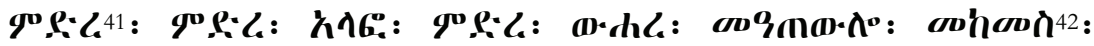

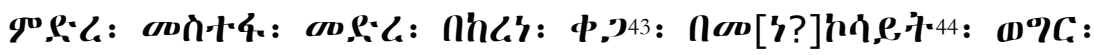

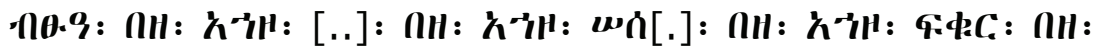

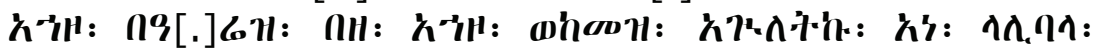
"77.

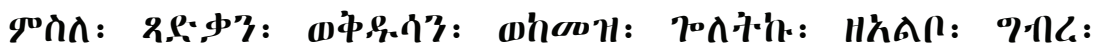

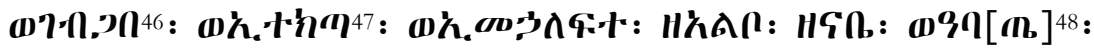

\footnotetext{
${ }^{38}$ Un autre exemple peut permettre de s'en convaincre. Le premier folio du deuxième fascicule photographié par Roger Schneider présente, au recto, l'acte no 2 de l'édition de Carlo Conti Rossini. Dans les photographies d'Alessandro Bausi, le premier folio est celui sur lequel figure une grande croix (Bausi, 1997 [1998] : 16). Il faut signaler que Roger Schneider a pu photographier certaines donations qu'Alessandro Bausi n'a pas pu voir, en particulier les actes nº2, 9, 14 et 31 .

39 Sic : $\mathbf{k} 7 \cdot \boldsymbol{n} \cdot \boldsymbol{n} \cdot \boldsymbol{h}$.

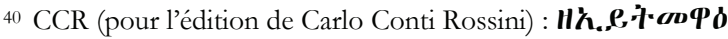

${ }^{41}$ CCR : omis

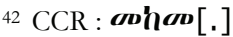

${ }^{43}$ CCR : [..]

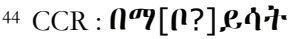

${ }^{45}$ CCR : omis

46 CCR : (D)'?

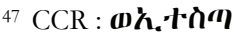




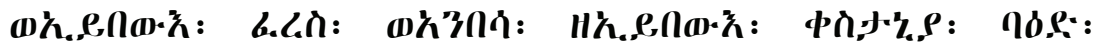

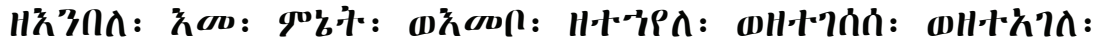

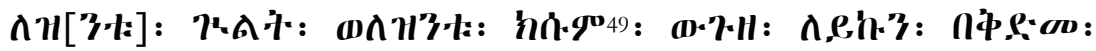

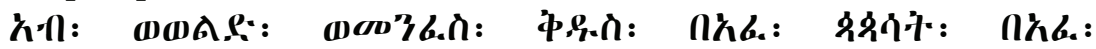

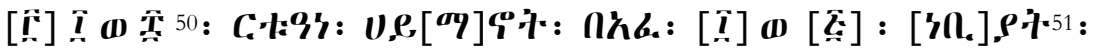

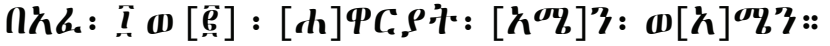

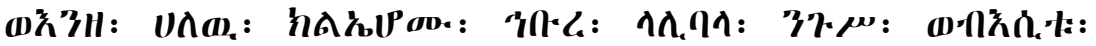

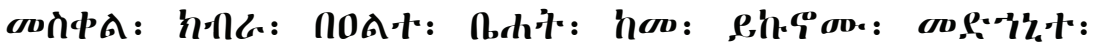

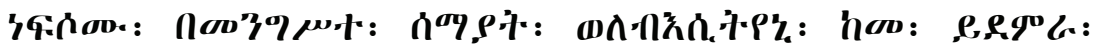

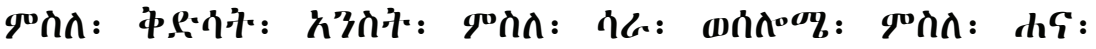

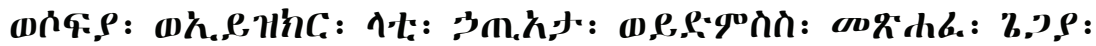

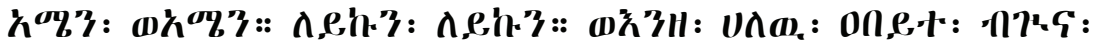

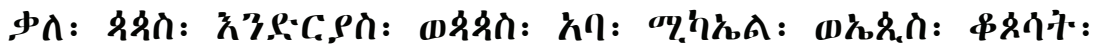

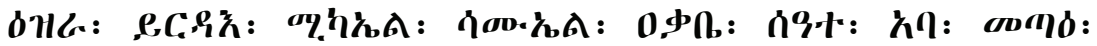

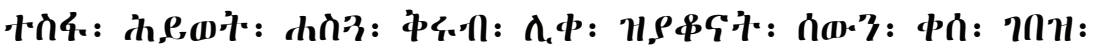

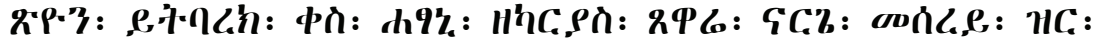

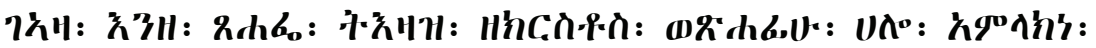

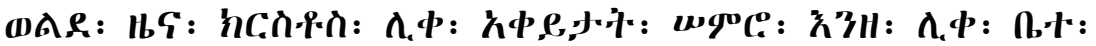

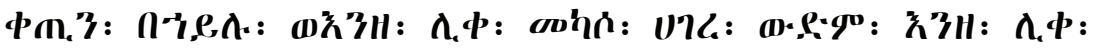

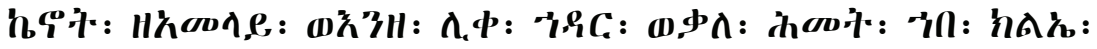

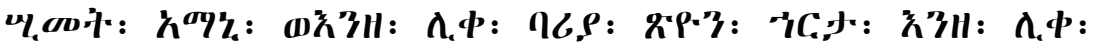

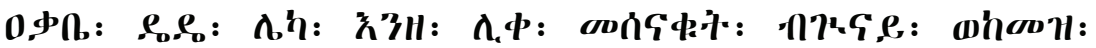

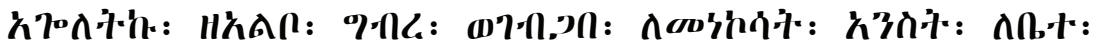

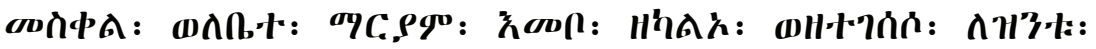

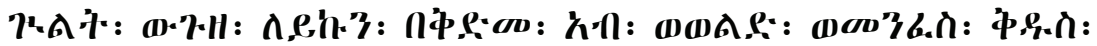

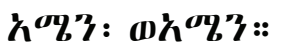

«En actions de grâces au Père, et au Fils et à l'Esprit Saint, en l'an de grâce $1089^{52}$, le 3 du mois de tăhassáś, j’ai donné en gyelt, j’ai assigné et j'ai souhaité, moi, le haḍani Lālibalā, dont le nom de règne est Gabra Masqal homme courageux et invicible par la puissance de la croix de Jésus Christ, fils de Morārā, fils de Zānśeyum, fils de 'Assedā, pour l'église de la Croix (Bēta Masqal) et l'église de Marie (Bēta Māryām), pour les vierges (Danāgel), les nonnes Eupraxie et Susanne, la terre de Dēra, la terre de 'Alāfo, la terre

\footnotetext{
48 CCR : 9qh. La lecture du manuscrit est confirmée par la comparaison avec le $g^{w}$ elt de Tanțawedem,

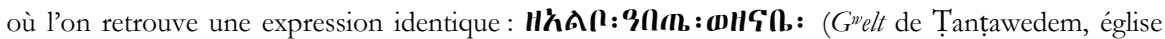
d'Urā Masqal Qefereyā, fol. 8r). Voir aussi l'acte de l'Évangile d'abbā Garimā II où l'on trouve

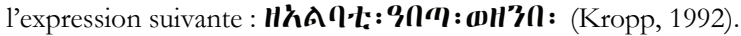

49 CCR : hग90

50 Le chiffre devrait être $\underset{\mathbf{T}}{\mathbf{P}} \boldsymbol{i} \boldsymbol{\Phi}$ :

51 CCR : omis

52 Conti Rossini (1901 : 188) corrige cette date en 1209. Ses arguments sont cependant assez faibles.
} 
de Weḥara, Ma'āṭawelo, Makamas, la terre de Mastafā, à Karan la terre de Qagā, à Manakoseyāt Wager ( ?), Beḍu'āas3, dans leur état. (... ?). Ainsi, j’ai donné en guelt, moi le roi Lālibalā, afin que le Christ se souvienne de moi dans son royaume et m'associe aux justes et aux saints, ainsi j'ai donné en $g^{w}$ elt, sans tribut et sans corvée, sans marché et sans passage, sans surveillant et sans personne qui exige les corvées. Que ni le cheval ni le lion n'entrent, que le chasseur étranger n'entre pas, à l'exception de la mère supérieure ${ }^{54}$. Quiconque outrepasse, prend et transgresse ce givelt et cette assignation, qu'il soit excommunié devant le Père, le Fils et l'Esprit Saint, par la bouche des patriarches, par la bouche des 318 orthodoxes, par la bouche des 15 prophètes, par la bouche des 12 apôtres, amen et amen.

Tandis que tous deux étaient unis, le roi Lālibalā et sa femme Masqal Kebrā, Ba'alta Bēhat (dame de Bēhat) ${ }^{55}$ afin que ce soit une délivrance pour leur âme dans le royaume des cieux, et pour mon épouse afin qu'elle soit associée aux saintes femmes, Sara et Salomé, Hanna et Sophia, et que son péché ne soit pas compté et que le livre de sa transgression soit détruit, amen et amen, ainsi soit-il, ainsi soit-il. Tandis que les grands du Begwenā sont : qāla pāppās (le porte-parole du métropolite ${ }^{56}$ ) 'Endreyās, pāppās (le métropolite) abbā Mikā'èl, 'èpis qoposāt (les évêques) 'Ezrā, Yerdā'e, Mikā'ēl et Sāmu'ēl, l'aqqābè

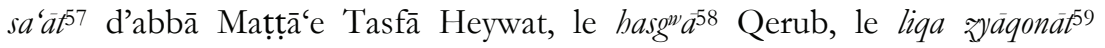
(l'archidiacre) Sawen, le qasa gabaz, Șeyon (l'administrateur de Sion) Yetbārak,

53 Bausi (2007 : 91) considère Wagr Beșu'ā comme un seul toponyme.

54 Crummey (2000 : 39) propose la traduction suivante: "And I granted [all this] as gult that it would be without tax and forced labor and that it not be given [?] and that roads may not cross it and that it would be without zänabé and abaké and that it may not be entered by a horse or a lion and that it not be entered by hunters, without [the permission] of the mother superior".

55 Conti Rossini, 1940 : 54 et note 2. Bihat était un village au voisinage du Šemazānā dont l'église avait une certaine notoriété puisqu'elle est mentionnée dans les actes de Baṣalota Mikāēèl comme étant un lieu religieusement important, makāna ba'alta Biḥät. Antonio Mordini (1961: 131) précise par ailleurs que Bihat est un village près de Gunā Gunā dans l'actuelle Érythrée. «Dame de Biḥat» est devenu un titre, notamment pour la reine Belēn Sabā, femme d'Amda Șeyon I (Conti Rossini, 1901 : 203 ). Ce titre se retrouve ensuite sous une forme abrégée - ba'altehät - pour certaines des épouses royales (Kropp, 2005 : 132). Voir aussi Kur \& Derat, 2007 : 844-845.

56 Littéralement, le pâppās est d'abord l'évêque d'Alexandrie, le patriarche, puis son équivalent dans la hiérarchie, ici le patriarche d'Éthiopie. Nous adoptons le terme de métropolite qui est celui employé dans tous les travaux pour désigner l'évêque égyptien nommé par le patriarche d'Alexandrie à la tête de l'église d'Éthiopie.

57 Littéralement, l'aqqäbè sa 'ät est le "gardien des heures ». Il s'agit d'un titre octroyé au supérieur de la communauté de Ahām, comme l'attestent les donations préservées dans l'évangéliaire de Dabra Libānos.

58 Une donation datée de 1328, préservée dans l'évangéliaire de Dabra Libānos, précise que le fils du roi 'Amda Șeyon (1314-1344), Bāḥra Asgad, est chef de l'Entertā, mais aussi mä'ekala bāḥer, mā'ekala

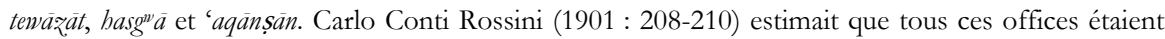
liés régionalement, et donnaient ainsi autorité sur tout le nord du royaume.

59 Autre forme pour liqa diyäqonät (voir Sokolinskaia, 2007 : 576). 


\section{Marie-Laure Derat}

le qasa haḍ̂ani (le prêtre du roi) Zakāryās, le șawārē nārgè masaraj60 (le porteur du récipient pour le parfum) Zer Ga'āzā, tandis que le șahafè te'ezāz. (le secrétaire des édits) (est) Zakrestos, et son secrétaire Halo 'Amlākna, fils de Zēna Krestos, le liqa 'Aqaytät (chef des 'Aqaytāt) ${ }^{61}$ Śamro, tandis que le liqa bèta qatțin (le chef des domestiques) (est) Bahaylu et tandis que le liqa makäso (est) Hagara Wedem, le liqa kènotó2 (le chef des prêtres) Za'amālāye, le liqa hadāro3 et le qäla hemmāt (est) 'Amāni pour ces deux fonctions, et tandis que le liqa Bäriyà (le chef des Bariyāen) (est) Șeyon Hartā, le liqa 'aqqäbè dèdè (le chef des gardiens des portes) Lèkā, tandis que le liqa masanäqut (le chef des masanqo ${ }^{65}$ ) (est) Beg'wenāy ${ }^{66}$. Ainsi, j’ai donné en gyelt sans tribut ni corvée aux nonnes, à l'église de la Croix et l'église de Marie. Si quelqu'un cache ou prend ce givelt, qu'il soit excommunié devant le Père, le Fils et l'Esprit Saint, amen et amen ».

L'une des questions que soulève cet acte concerne la date à laquelle la donation a été faite : 1089, qui est contradictoire avec la chronologie du règne de Lālibalā, telle que nous la connaissons (c'est-à-dire fin XII'-1225- ?) ${ }^{67}$. La lecture du document confirme ce que Carlo Conti Rossini avait retenu dans son édition. Celle-ci n'est donc pas fautive. Pour résoudre la question, Carlo Conti Rossini proposait purement et simplement de changer le texte et de substituer le chiffre ${ }^{\mathbf{T}}$ par deux autres, $\stackrel{\mathbb{P}}{\mathbf{P}}$, afin de restituer une toute autre date : 1209. Il fondait son raisonnement sur les métropolites ayant exercé leur charge au cours du règne de Lālibalā. Dans l'acte $n^{\circ} 6$, en effet, il s'agit du métropolite Mikā'èl, dont on sait par l'Histoire des

${ }^{60}$ Ce titre figure également dans le Règlement de la tonsure (Ser'ata Q Q erḥät), qui présente les dignitaires qui doivent être présents au moment de la tonsure du nouveau roi et la manière dont la cérémonie doit se dérouler. Voir Dillman, 1884 : 18 ; Sciarrino, 1994.

${ }^{61}$ Parmi les documents compilés dans le Liber Axumae, on trouve un liqa 'Aqaytät. Un peu plus haut, l'on apprend que la terre de Ad Aqayt a été achetée pour les ecclésiastiques d'Aksum. Le liqa 'Aqaytät serait donc le chef de cette région ou de ses habitants (Conti Rossini, 1909-10 : 52-62).

62 Autre forme pour liqa kähenät (voir Sokolinskaia, 2007: 576).

${ }^{63}$ Evgenia Sokolonskaia (2007: 576) avance l'idée qu'il pourrait s'agir d'un corps de troupe.

${ }^{64}$ Il s'agit là d'une fonction qui a un ancrage soit spatial soit ethnique, puisque les Bāryā constituent un groupe de population installé dans le nord-est de l'Érythrée actuelle (Conti Rossini, 1895 : 35-45). On trouve, dans l'Histoire des guerres d'Amda Șeyon, un chef des soldats de Bāryā (Marrassini, 1993: 114-115 ; Kropp, 1994 : 34 (texte), 40 (trad.)). D'autres estiment que bāryā renvoie ici aux esclaves, ainsi désignés à partir de la fin du XVIe siècle, sans doute par glissement de l'ethnonyme au substantif. Mais avant le XVI $I^{e}$ siècle, aucun document ne permet d'induire que les populations Bāryā désignent exclusivement des esclaves (Conti Rossini, 1907 : 29-30 (texte), p. 34-35 (trad.). Ludolf, 1698-1699 : col. 11, 40 ; Pankhurst, $1977:$ 12, 37 note 94).

65 Instrument de musique, violon à une corde. Plus tard, au cours du règne de Zar'a Yă’eqob, on rencontre des 'az̧märi räs, ₹än 'az̧märi et ba'ala baganä (Kropp, 2005 : 135).

${ }^{66} \mathrm{Il}$ peut ici s'agir d'un nom ainsi que nous avons choisi de le restituer dans la traduction, d'autant que dans l'acte $\mathrm{n}^{\circ} 7$, on trouve un liqa masanqo qui est présenté comme Walda Beg'wenāy, donc « fils de Beg'wenāy ». Il faut toutefois noter que dans l'acte n ${ }^{\circ} 8$ de l'Évangile de Dabra Libānos, on trouve un 'aqqäbè sa'ät Yerde'anna Krestos qui à la suite de son nom se dit Begwenāy de Șelālā (Conti Rossini, 1901 : 192). Conti Rossini posait la question de savoir si ce Yerde'anna Krestos ne se présentait pas ainsi comme un homme du Beg'wenā de la région de Șelālā.

67 Voir supra. 
Patriarches d'Alexandrie qu'il fut chassé d'Éthiopie la cinquième année de son séjour ${ }^{68}$, et remplacé par Yeshaq, nommé en $1210^{69}$, avant que Giyorgis, qui est cité dans l'acte $\mathrm{n}^{\circ} 7$, daté de 1225 , tout comme dans le Kebra Nagaśt $7^{0}$, n'exerce sa charge. Mikāēl fut donc nommé vers 1203 et occupa ses fonctions de métropolite jusqu'en 1208-1209 approximativement ${ }^{71}$. Si la correction de Carlo Conti Rossini respecte une logique chronologique, elle n'est pas pour autant satisfaisante. Il reste donc à comprendre cette date de 1089, tant on sait par ailleurs que l'an de grâce ne renvoie pas forcément à un calendrier unique, comme l'atteste l'acte $n^{\circ} 7$, même si l'on peut retenir que la donation de Lâlibalā, contemporaine de la charge de Mikā’èl, date d'envion 1203/04-1208/0972.

Par ailleurs, l'identification des églises bénéficiaires de l'acte $\mathrm{n}^{\circ} 6$ pose problème. À 'Ahām, se trouve une églisée dédiée à Marie ${ }^{73}$. Pourtant on peut se demander pourquoi l'acte ne précise pas qu'il s'agit de cette église-là, de la même manière que dans le deuxième acte, où le texte est le suivant : «j'ai donné à Mațțā'e de 'Ahām ». Pourrait-il s'agir des églises du premier groupe du site de Lālibalā, ces trois monuments associés dans une même cour, situés en contre-bas de l'église de Bēta Madhānē Alam ? Les noms cités sont les mêmes : Bēta Masqal, Bēta Māryām et Danāgel (les Vierges). L'association de ces trois noms permet de poser cette hypothèse, en proposant par conséquent de voir dans les Vierges, non pas une référence à un groupe de nonnes, mais un toponyme.

Deux objections sont toutefois à retenir. Tout d'abord, parmi les terres octroyées aux églises, une région est identifiable, celle de Karan. Dans le recueil de donations de Tanțawedem, préservé à 'Urā Masqal, l'église de Qefereyā - autre nom pour 'Urā Masqal - aujourd'hui sur la frontière entre l'Éthiopie et l'Érythrée, est située dans la région de $\operatorname{Karan}^{74}$. D'autre part, l'acte $\mathrm{n}^{\circ} 10$ conservé dans l'Évangile de Dabra Libānos, datant de Yekuno 'Amlāk (1270-1285), fait référence à la spoliation des terres attribuées par le roi Lālibalā à Bēta Masqal, Bēta Māryām et aux Vierges, par le śeyum de Dabra Mā‘eșo75. Ce toponyme n'est pas inconnu. Il figure dans la chronique de Ba'eda Māryām (1468-1478) comme un lieu de relégation. Dans les documents compilés par Carlo Conti Rossini dans le Liber Axumae, Dabra Mā‘eșo apparait comme faisant partie des régions qui doivent des

68 Perruchon, 1898-1899: 79 ; Khater \& Burmester, $1970: 186$.

69 Perruchon, 1898-1899 : 85 ; Khater \& Burmester, $1970: 192$.

70 Bezold, 1909 : 138.

71 Une ambassade chargée d'enquêter sur le départ du métrépolite Mikā’ēl revint après un an au Caire. Le retour de l'ambassade est datée de «l'an 606 de l'hégire, correspondant à l'année 926 de l'ère des saints martyrs (1209-1210)" dans l'Histoire des Patriarches d'Alexandrie (Perruchon, 1898-1899: 82 ; Khater \& Burmester, $1970: 189)$.

72 Alessandro Bausi a probablement effectué le même raisonnement puisqu'il considère que l'acte $\mathrm{n}^{\circ} 6$ est à dater de 1205/1209 (Bausi, 2007 : 81).

${ }^{73}$ Dans le village de 'Ahām, l'église, qui abrite des vestiges d'une église antique, est dédiée à Marie (Conti Rossini, $1901:$ 178)

${ }^{74}$ G"elt de Ṭanțawedem, église d'Urā Masqal, fol. 7r. Qefereyā figure dans le Liber Axumae comme une zone de passage pour l'acheminement du bois depuis le Mambartā jusqu'à Aksum, et est présenté comme étant au voisinage du Gelo Mākedā. Voir Conti Rossini, 1909-10 : 11 (texte), 10 (trad.).

75 Conti Rossini, 1901 : 194. 
«servitudes » (gebr) à l'église d'Aksum ${ }^{76}$ et figure aussi parmi les terres allouées à cette même église par le roi 'Anbasā $\mathrm{Wedem}^{77}$. Il y a donc tout lieu de penser que le seyum de Dabra Mā‘eșo exerçait sa juridiction sur une région proche d'Aksum et que les terres qu'il a spoliées au cours du règne de Yekuno 'Amlāk étaient proches de sa région. Par conséquent, la donation du roi Lālibalā concerne les églises de Marie et de la Croix de 'Ahām qui sont sous la juridiction de nonnes, les vierges désignant les moniales et non pas un toponyme.

En ce qui concerne l'acte $n^{\circ} 7$, Carlo Conti Rossini présente une édition réalisée à partir des deux copies du texte qu'il a pu consulter et qu'il dénomme $\mathrm{A}$ et $\mathrm{B}$. A correspond à la copie qui figure dans le deuxième fascicule et est sans doute l'original. B est le document inscrit dans le premier fascicule du manuscrit et est donc une copie tardive. L'édition présentée ici ne se fonde que sur la version A de Conti Rossini et propose de restituer le document tel qu'il est, en prenant en compte les lectures de Conti Rossini à partir de $\mathrm{B}$ quand le document est trop endommagé et certaines lettres illisibles dans les dernières lignes.

Acte $\mathbf{n}^{\circ} 7$

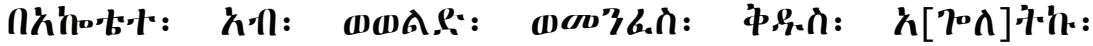

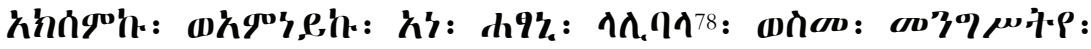

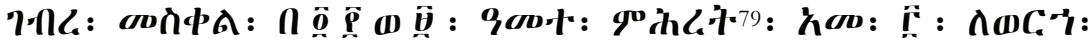

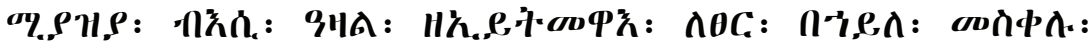

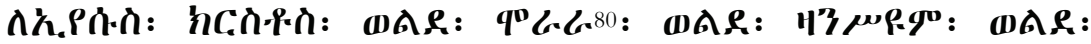

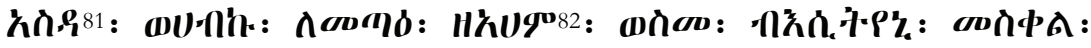

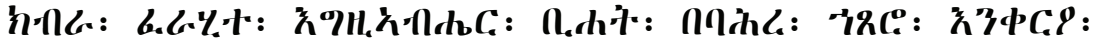

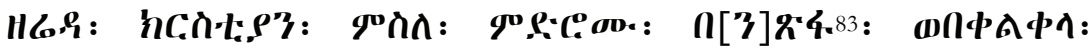

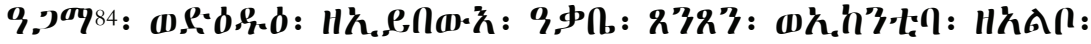
9नीL: त

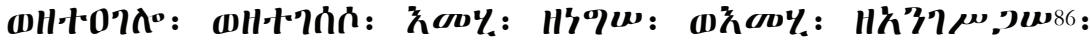

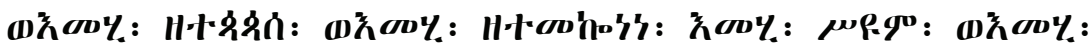

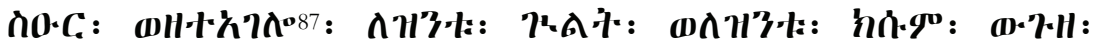

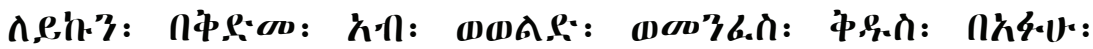
त乡

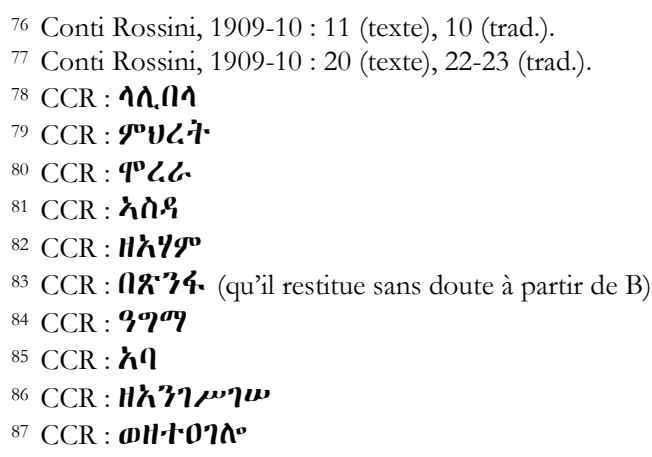


1,

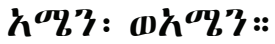

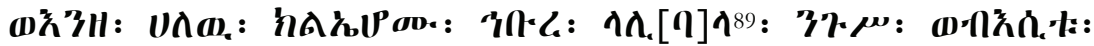

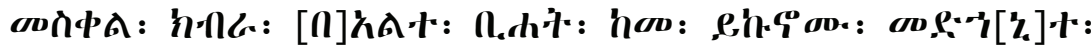
दF:

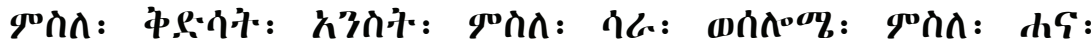

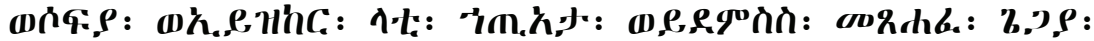

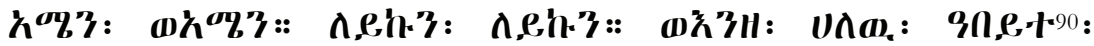

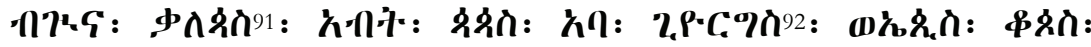

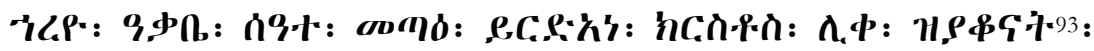

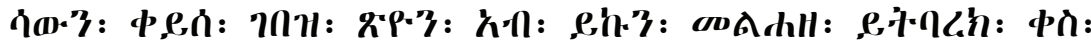

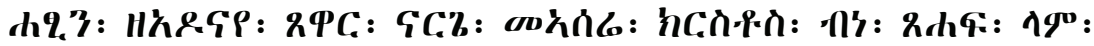

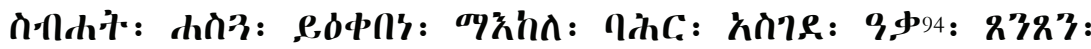

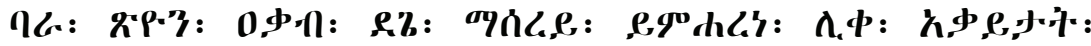

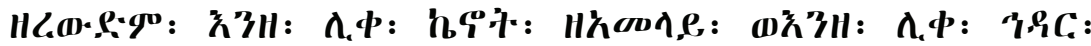
Pq०: त, क:

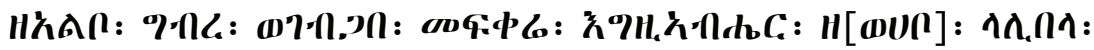

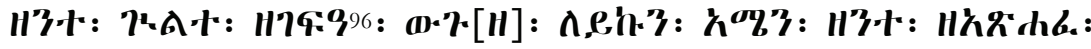

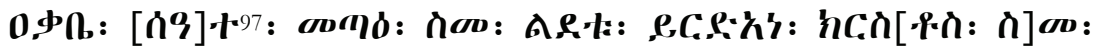

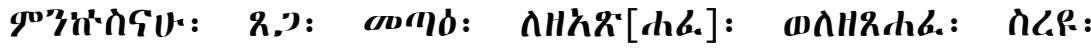

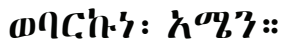

«En actions de grâces au Père et au Fils et à l'Esprit Saint, en l'an de grâce 409 (1225), le 3 du mois de miyāayaä, j’ai donné en g"elt, j’ai assigné et j’ai délimité, moi, le hạậani Lālibalā, dont le nom de règne est Gabra Masqal, homme courageux qui n'est pas vaincu par l'ennemi, par la force de la Croix de Jésus-Christ, fils de Morārā, fils de Zānśeyum, fils de 'Assedā, et le nom de ma femme (est) Masqal Kebrā, qui craint le Seigneur, j’ai donné à Matțāâe de 'Ahām: Bihat, du rivage d'Huāṣaro, 'Enqer'o ${ }^{98}$, Zarēdā chrétien ${ }^{99}$, avec leurs terres, à la limite et au ravin d'Agāmā et De'edu'e, sans taxes pour

\footnotetext{
88 CCR : omis

89 CCR : $\boldsymbol{\Lambda \Lambda \Lambda \Lambda}$

${ }_{90}$ CCR : on,er.

91 Que l'on peut aisément restituer comme : $\boldsymbol{\jmath} \mathbf{\Lambda}: \boldsymbol{\ell}[\boldsymbol{\ell}] \boldsymbol{n}$. À moins que cela soit une abbréviation en usage à cette période.

92 CCR : $\mathbf{Z}, \boldsymbol{P} \cdot \boldsymbol{C}: \boldsymbol{\eta}, \boldsymbol{\Lambda}$

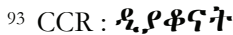

${ }^{94}$ Le 'ayn porte à la fois les marques du $4^{\mathrm{e}}$ ordre $(\boldsymbol{Y})$ et du $\sigma^{\mathrm{e}}$ ordre $(\boldsymbol{\boldsymbol { O }})$, sans doute après correction.

95 La forme devrait être : $\boldsymbol{\Lambda} \boldsymbol{7} \cdot \boldsymbol{\Lambda} \boldsymbol{\nabla} \cdot \boldsymbol{h}$.

96 CCR : H'79:0

97 CCR : nor.

98 On retrouve ce toponyme dans d'autres actes de l'Évangile de Dabra Libānos, voir Bausi, 2007 : 85.

99 On retrouve ce toponyme dans d'autres actes de l'Évangile de Dabra Libānos, voir Bausi, 2007 : 91.
} 


\section{Marie-Laure Derat}

l'étranger ${ }^{100}$. Que l'aqqābè șenșen n'entre pas, ni le kantibā, à l'exception de l'abbé de Mațțāe. Quiconque l'outrepasse, le transgresse ou le prend, qu'il soit celui qui règne, celui qui occasionne des troubles, celui qui est pāppās, ou celui qui gouverne, qu'il soit nommé ou destitué, que celui qui transgresse ce $g^{y}$ elt et cette assignation soit excommunié devant le Père, le Fils et l'Esprit Saint, par la bouche de notre père Mațtāe, par la bouche des patriarches, par la bouche des 318 Orthodoxes, par la bouche des 15 Prophètes, par la bouche des 12 Apôtres, amen et amen.

Tandis qu'ils étaient tous deux unis, le roi Lālibalā et sa femme Masqal Kebrā, Ba'alta Biḥat (dame de Biḥat), afin que cela soit pour leur âme une délivrance dans le royaume des cieux, et pour ma femme afin qu'elle soit associée aux saintes, avec Sara et Salomé, Hanna et Sophia, et que son péché ne soit pas compté et que le livre de sa transgression soit détruit, amen et amen, ainsi soit-il, ainsi soit-il. Tandis que les grands du Beg'wenā étaient : le qāla pāppās (le porte-parole du métropolite) 'Abt, le pāppāàs (le métropolite) abbā Giyorgis, et l'epis qopos (l'évêque) Harayo, l'aqqäbē sa'ät de Mațțāe Yerde'anna Krestos, le liqa zyāqonāt (l'archidiacre) Sawen, le qaysa gabaz Seyon (l'administrateur de Sion) 'Ab Yekun, le malhąa Yetbārak, le qasa ha d̦in (le prêtre du roi) Za'adonāy, le șawār nārgè ma'asarè (le porteur du récipient pour le parfum) Krestos Bena, le șahaf làm (le secrétaire du troupeau) ${ }^{101}$ Sebhat, le hasgo"à Ye'eqabana, le mä'ekala bāḥer102 'Asgada, le liqā șanșan (le chef du chasse-mouche) ${ }^{103}$ Bārā Ṣeyon, le 'aqāb dagè màsaray Yemḥeranna, le liqa 'A qāytāt (le chef des 'Aqāytāt) Zarawedem, tandis que le liqa kènot (le chef des prêtres) (est) Za'amalāye, et tandis que le liqa hedar (est) Yamo, le liqa masanqo (le chef des masanqo) le fils de Begwenāy. Ainsi, j'ai donné en givelt sans tribut ni travail forcé. Bien-aimé du Seigneur celui qui a donné, Lālibalā, ce gyelt. Celui qui agit mal, qu'il soit excommunié, amen. Celui qui a fait écrire cela (est) l'aqqäbè sa'ät de Mațtāa'e dont le nom de baptême est Yerde'anna Krestos, et le nom de moine Șagā Mațțāee. Celui qui a fait écrire et celui qui écrit, qu'ils soient pardonnés et bénis, amen ».

\section{Vers une géographie du royaume zāgwē}

Ces trois textes sont les seuls documents qui dévoilent, avec parcimonie, le fonctionnement du royaume chrétien d'Éthiopie au cours du règne de Lālibalā. Le

${ }^{100}$ La construction de la phrase dans le texte ge'ez est assez étrange.

${ }^{101} \mathrm{La}$ documentation ultérieure permet d'estimer que le șaḥaf lām (șahafaläm) est un gouverneur régional, comme cela est attesté ensuite pour l'Amharā, le Šawā, le Dāmot (Perruchon, 1893: 16, 101, 111-112, 116, 145, 153 ; Marrassini, 1993 : 52-53 ; Kropp, 1994 : 4 ; Kropp, 2005 : 136).

${ }^{102}$ Littéralement le milieu de la côte ou de la mer, qui selon Sevir Chernetsov désigne à la fois la région entre la côte et l'hinterland appelée Hāāāsēn, et le titre de celui qui dirige cette région (Chernetsov, 2003b : 444).

${ }^{103}$ Est-ce une autre forme pour l'aqqābè șanșan ou 'āqāṣên, gardien du chasse-mouche, titre donné au gouverneur de la région de l'Endartā? (Chernetsov, 2003a : 290). 
reste de la documentation écrite contemporaine de ce souverain - les dédicaces des manbara tābot - ne concerne qu'un seul lieu, Lālibalā, et un aspect du règne, la dévotion religieuse de notre souverain et son accession à la sainteté104. Quant à l'Histoire des Patriarches d'Alexandrie, et plus précisément la biographie du patriarche Jean VI, elle témoigne certes au sujet de la capitale du roi, mais selon une interprétation exogène du fonctionnement de l'État éthiopien à cette période. Tant et si bien que ce texte introduit des distorsions qu'il faut d'abord distinguer avant de pouvoir tirer des conclusions. Les informations transmises par les donations de terres de Lālibalā relèvent d'au moins deux registres. D'une part, les églises dotées et les terres qui leur sont allouées dessinent un territoire sur lequel s'exerce l'autorité du souverain. Mais est-ce que ce territoire est traité de manière uniforme ? D'autre part, la liste des dignitaires invoqués comme témoins des chartes présente une organisation politique et religieuse, rassemblée sous l'appellation "grands du Beg'wenā », qui semble figurer le centre du royaume, aussi bien d'un point de vue politique que géopolitique. Quel est donc ce centre?

L'ancrage territorial de la dynastie zāg ${ }^{\mathrm{w}} \mathrm{e}$ a fait l'objet de peu de débats. L'usage est de considérer que les $\mathrm{Z}_{\bar{a}}^{\mathrm{w}}{ }^{\mathrm{w}} \mathrm{e}$ ont exercé leur pouvoir depuis la région du Beg ${ }^{\mathrm{w}}$ enā-Lāstā, faisant glisser le centre du royaume de la région d'Aksum à celle de Lālibalā, considérée par beaucoup comme la capitale du royaume zāgiēe Si l'on prend en compte non seulement les fondations d'églises - qui sont concentrées au Beg'wenā-Lāstā - mais aussi les donations foncières qui ne concernent pour le moment que trois églises, celle de Bēta Madhānē 'Alam à Lālibalā, celle de Dabra Libānos de 'Ahām, dans l'actuelle Érythrée, et celle d'Urā Masqal, sur la frontière entre l'Éthiopie et l'Érythrée, alors il faut revoir la question du territoire sur lequel règne les Zāậēe, et en premier lieu le roi Lālibalā. Certes ce dernier fonde des églises sur le site qui porte aujourd'hui son nom. Ce qui constitue une réelle poussée du royaume vers le Sud. Mais les donations de terre pour les églises du Nord montrent que, pour le moins, Lālibalā continuait de donner des gages à ses sujets du Nord. De même que son mariage avec Masqal Kebrā, dame de Bihạt, relève probablement de cette politique. Bihat est une localité importante du Šemazānā, située au sud de l'actuelle Érythrée, près de Gunā Gunā ${ }^{105}$. Masqal Kebrā représente donc probablement la noblesse du Nord à laquelle le roi Lālibalā s'allie par son mariage.

Alors faut-il distinguer entre fondation et donation? La documentation est trop lacunaire pour répondre définitivement à cette question. Mais un argument de bon sens peut être invoqué : les rois fondent des églises dans les régions où il y a peu d'édifices religieux. En revanche, lorsque les églises préexistent, il leur est loisible de faire des donations pour renouveler le lien entre celles-ci et le royaume. Dans les deux cas, la marque royale est réelle et signale que les régions dotées sont sous l'autorité du souverain. Par conséquent, le territoire sur lequel le roi Lālibalā règne ne se limite pas à la région du Beg ${ }^{\mathrm{w}}$ enā-Lāstā, mais couvre aussi le Nord du

${ }^{104}$ Voir l'article de Claire Bosc-Tiessé dans ce volume. ${ }^{105}$ Mordini, $1961: 131$. 


\section{Marie-Laure Derat}

royaume. Ce n'est pas tant que le royaume chrétien a glissé vers le Sud, mais qu'il s'est étendu. À moins de considérer que c'est depuis la région du Begowenā-Lāstā que Lālibalā et les rois zāg'wē règnent.

Dans les actes $\mathrm{n}^{\circ} 6$ et $\mathrm{n}^{\circ} 7$, les dignitaires évoqués comme témoins de la donation sont désignés sous l'expression «les grands du Begwenā». Le Beg"wenā correspond en partie à la région de l'actuel Lāstā, où les églises de Lālibalā ont été excavées $^{106}$. D'après l'Histoire des patriarches d'Alexandrie, au cours du règne de Lālibalā, la capitale du royaume se situait dans une ville appelée Adfa, toponyme que l'on identifie à une vallée située en contre-bas des églises de Lālibalāi ${ }^{107}$. Il faut reconnaître au chroniqueur égyptien la qualité de son information puisque les actes de Yemrehanna Krestos situent aussi la région capitale du pouvoir à Adafāan ${ }^{108}$. Quant aux actes de Lālibalā, ils localisent la ville sainte du roi à Rohā (assimilée dans plusieurs documents à Warwar), que l'on identifie avec le site où furent creusées les églises de Lālibalā ${ }^{109}$. À partir de là, il est aisé de conclure que la région centrale du pouvoir des Zāg'wēétait précisément celle où le roi Lālibalā fonda les églises qui portent aujourd'hui son nom.

Mais les « grands du Beg'wenā »n'exercent pas seulement leur pouvoir sur cette région. Ces dignitaires, au nombre de 18 dans les deux donations de l'évangéliaire de Dabra Libānos, sont en majorité cités pour les fonctions qu'ils occupent, en particulier des fonctions religieuses (prêtre du roi, chef des diacres) mais aussi laïques (gardien du chasse-mouche, maitre de cérémonie). Certains dignitaires ont au contraire des charges dont l'ancrage est régional : c'est particulièrement vrai pour l'aqqābè sa'āt de 'Ahām, supérieur de l'église située au Šemazānā; le qaysa gabaz. Seyon, supérieur de l'église d'Aksum; le liqa Baryā probablement chef des populations Baryā, occupant le nord-est de l'actuelle Érythrée ${ }^{110}$; le ma'ekala bāḥer, dont la charge est localisée au Tegre $\overline{-1}^{-111}$. Par ailleurs, toujours d'après les actes $n^{\circ} 6$ et $\mathrm{n}^{\circ} 7$, le roi Lālibalā est marié à une femme qui est issue de la noblesse du nord du royaume. Tous ces éléments dessinent donc une géographie du royaume qui ne se concentre pas uniquement sur le $\mathrm{Beg}^{\mathrm{w}} \mathrm{en} \bar{a}$, mais qui intègre également de manière très organique la région du Tegrē et les régions plus septentrionales. Si bien que l'expression « grands du Beg ${ }^{\mathrm{w}}$ enā » doit peut-être être comprise autrement : non pas les dignitaires de la région du Beg ${ }^{\mathrm{w}}$ enā, mais les dignitaires d'un État qui se nomme Beg'wenā. Ce qui revient à poser l'hypothèse que le royaume d'Éthiopie était alors le royaume du Beg'wenā, le Beg'wenā étant bien plus qu'une région et plus aussi que la région centrale du pouvoir.

\footnotetext{
106 Derat, 2009 ; Bosc-Tiessé, 2009.

${ }^{107}$ Notamment Taddesse Tamrat, 1972 : 59 note 5 . Il y a un bien une vallée qui porte toujours le nom d'Adafā en contre-bas de la ville de Lālibalā, mais aucun vestige ne permet toutefois d'assurer qu'il s'agit de la capitale évoquée par les textes historiques.

${ }^{108}$ Marrassini, $1995:$ 44/80.

109 Perruchon, $1892: 12 / 77,52 / 118$.

${ }^{110}$ Conti Rossini, 1895 : 35-45.

${ }^{111}$ Kropp, $1994: 5$ note 34.
} 
Il ne s'agit pas ici de mettre en doute l'existence d'une région, le Begiwenā, qui se superpose plus ou moins à l'actuel Lāstā. La région comme sa localisation sont attestées historiquement. Toutefois, si l'on se contente de comprendre l'expression les « grands du Beg ${ }^{\mathrm{w}}$ enā » comme signalant les dignitaires du royaume et ramenant celui-ci à la seule région du Beg ${ }^{\mathrm{w}}$ enā, alors il y a toutes les chances que l'on fasse un contresens. Soit, comme nous l'avons dit plus haut, le Beg ${ }^{\mathrm{w}}$ enā dans ce cas fait référence à une entité autre que la région - comme si l'expression "grands du Begwenā » signifiait " grands du royaume » ${ }^{112}$, soit c'est l'origine géographique des dignitaires sur laquelle il est mis l'accent, ce qui signifierait que le roi Lālibalā aurait installé à la tête des plus hauts échelons de l'État et de l'Église, exclusivement des personnes originaires du $\mathrm{Beg}^{\mathrm{w}}$ enā. Un détail de l'acte $\mathrm{n}^{\circ} 8$ de l'Évangile de Dabra Libānos justifie cette discussion. On trouve en effet un 'aqqābè sa'āt Yerde'anna Krestos qui à la suite de son nom se dit "Beg ${ }^{\mathrm{w}}$ enāy de Șelālā » ${ }^{113}$. Yerde'anna Krestos occupait sa charge d'aqqäbè sa'ät de 'Ahām au cours du règne de Lālibalā (comme l'atteste l'acte $n^{\circ} 7$ ). N'étant pas en mesure de localiser Șelālā, on ne peut être définitif. Mais on peut comprendre cette indication comme une manière de se présenter comme un officier du royaume, ou comme un homme originaire du $\mathrm{Beg}^{\mathrm{w}}$ enā. Il faut toutefois remarquer que le métropolite de l'Église éthiopienne, moine égyptien consacré évêque d'Éthiopie par le patriarche d'Alexandrie, qu'on ne peut donc pas soupçonner d'être originaire du Beg'wenā, est intégré dans la liste des grands du Begiwenā. Il y a donc bien dans cette expression une référence autre que purement géographique.

Pour conclure, les donations du roi Lālibalā ne donnent certes pas les limites précises du territoire sur lequel ce souverain exerçait son autorité. Mais on voit émerger deux pôles : la région du Begwenā, où ce souverain fonde des églises, et la région du Šemazānā, où il fait des donations de terres et dont est originaire sa femme. On pourrait se contenter alors de dessiner un royaume zāgie è au tournant du XIII ${ }^{e}$ siècle prenant en écharpe ces deux régions. Mais rien ne nous dit qu'elles formaient un territoire unique. Il pourrait tout à fait s'agir de deux zones d'influence zāgwēe, les régions intersticielles pouvant échapper au contrôle de la dynastie. Au sein de ces deux pôles, y a-t-il un centre? L'expression "grands du Begwenā» pourrait le laisser penser, mais nous avons remarqué à quel point la liste des dignitaires appartenant à ce groupe, est loin de désigner la région du Begiwenā comme centrale, sauf à estimer que ces dignitaires sont originaires du Begwenā, ce que l'exemple du métropolite vient contredire. La structure administrative que renvoient ces donations de terre paraît donc déséquilibrée, au profit des régions septentrionales. Au sein du groupe des dignitaires du royaume, il manque par exemple l'ecclésiastique en charge des églises de Lālibalā, celui qui est désigné sous le titre de liqa kahnāt de Warwar dans la documentation plus tardive ${ }^{114}$. On pourrait

\footnotetext{
${ }^{112}$ Voir par exemple la mention des «grands du royaume » dans le récit de la donation faite par le roi Dāwit à l'église de Bētaleḥ̄em, Laḥa Maryam, église Bēta Lehēm, Gayent, mf. Donald Crummey Illinois/IES 88.XXIV.9 (Bosc-Tiessé \& Derat, 2010).

${ }^{113}$ Conti Rossini, $1901: 192$.

${ }^{114}$ Bosc-Tiessé, 2009 : 108.
} 


\section{Marie-Laure Derat}

opposer à ce déséquilibre apparent que les donations de terres octroyées à l'église de Dabra Libānos invoquent comme témoins et garants des officiers qui ont justement à voir avec le territoire concerné. Mais ce serait oublier l'expression "grands du

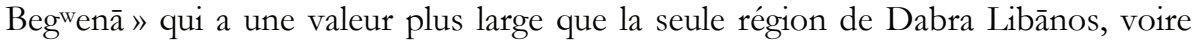
même, si l'on n'accrédite pas l'hypothèse formulée plus haut, désignerait l'actuel Lāstā. Surtout, toutes les fonctions n'ont pas été identifiées ni même spatialisées - le malhaza, le sahaf làm, le liqa 'Aqaytät, le liqa hedar - il faut donc se garder de conclure trop hâtivement.

\section{Bibliographie}

Atiya A. S., Abd al-Masih Y., Burmester O.H.E., 1948, History of the Patriarchs of the Egyptian church, known as the History of the Holy Church by Sawirus ibn al-Mukaffa, Bishop of al-Asmunin, Le Caire.

Bausi A., 1997 [1998], Su alcuni manoscritti presso comunità monastiche dell'Eritrea. Parte terza. Dabra Libanos, Rassegna di Studi Etiopici, 41, 13-56.

Bausi A., 2005, Däbrä Libanos, in Encyclopaedia Aethiopica, Uhlig S. ed., Wiesbaden, 2, 28-29.

Bausi A., 2007, Un indice dell'Evangelo d'oro di Dabra Libānos (Šemazānā, Akkala Guzāy, Eritrea), Aethiopica, 10, 81-91.

Bezold C., 1909, Kebrä Nägäśt. Die Herrlichkeit der Könige, Abhandlungen der philosophisch-philologischen Klasse der Königlich Bayerischen Akademie der Wissenschaften 23.

Bosc-Tiessé C., 2009, Gouverner et définir un territoire. Géopolitique, art et production manuscrite au Lasta entre 1667 et 1768, Annales d'Éthiopie, 24, 87148.

Bosc-Tiessé C. \& Derat M.-L., 2010, Acts of writing and authority in Bəgwona-Lasta between the fifteenth and the eighteenth centuries: a regional administration comes to light, Northeast African Studies, sous presse.

Chernetsov S., 2003a, Aqașen, in Encyclopaedia Aethiopica, Uhlig S. ed., Wiesbaden, 1, 290.

Chernetsov S., 2003b, Baḥ̣r nägaš, in Encyclopaedia Aethiopica, Uhlig S. ed., Wiesbaden, 1, 444.

Conti Rossini C., 1895, Appunti ed osservazioni sopra i rei Zāguē, Rendiconti della Reale Accademia dei Lincei, ser. 5, 4, 341-359.

Conti Rossini C., 1896-1897, Sulla dinastia Zâguê, L’Oriente, 2, 3-4, 144-159.

Conti Rossini C., 1901, L'evangelo d'oro di Dabra Libanos, Rendiconti della Reale Accademia dei Lincei, serie 5, 10, 177-219.

Conti Rossini C., 1902, Lettera a J. Halévy sulla caduta degli Zague, Revue Sémitique, 10, 373-377.

Conti Rossini C., 1903, Lettera a J. Halévy sullo statuto attuale della questione degli Zague, Revue Sémitique, 9, 325-331. 
Conti Rossini C., 1904, Gädlä Yared seu acta sancti Yared, Paris (CSCO, Script. Aeth. 17).

Conti Rossini C., 1907, Historia regis Sarșa Dengel (Malak Sagad). Accedit Historia gentis Galla curante Ignazio Guidi, Paris (CSCO 20-21, Script. Aeth. 3-4).

Conti Rossini C., 1909-1910, Documenta ad illustrandam historiam. Vol. 1: Liber Axumae. Paris \& Leipzig, (CSCO 54-58,Script. Aeth. 24-27).

Conti Rossini C., 1914, Notice sur les manuscrits éthiopiens de la collection d'Abbadie, ext. Journal Asiatique, Paris.

Conti Rossini C., 1916, Principi di diritto consuetudinario dell'Eritrea, Rome.

Conti Rossini C., 1922, La caduta della dinastia Zague e la versione amarica del Be'ela Nagaśt, Rendiconti della Reale Accademia dei Lincei, 21, 279-314.

Conti Rossini C., 1943, Gli atti di Re Na'akueto La'āb, Annali, Istituto Superiore Orientale di Napoli, ns 2, 105-232.

Crummey D., 2000, Land and Society in the Christian Kingdom of Ethiopia from the Thirteenth to the Twentieth Century, Oxford.

Derat M.-L., 2006, The Acts of King Lalibäla: Structure, Literary Models and Dating Elements, in Proceedings of the XVth International Conference of Ethiopian Studies, Hamburg, July 20-25, 2003, Uhlig, S. ed., Wiesbaden, 561-568.

Derat M.-L., 2009, Du Begwenā au Lāstā : centre et périphérie dans le royaume d'Éthiopie du XIII' au XVI siècle, Annales d'Éthiopie, 24, 65-86.

Derat M.-L., 2010, The Zagwe dynasty and King Yemrehanna Krestos, 10 ${ }^{\text {th }}{ }^{\text {-1 }} 3^{\text {th }}$ centuries, in Balicka-Witakowska E. \& Gervers M. (ed.), Yemrehanna Krestos (à paraître).

Dillmann A., 1884, Über die Regierung, insbesondere dir Kirchenordnung des Königs Zar'a Jacob”, Abhandlungen der Königlichen Akademie der Wissenschaften zu Berlin, Philosophisch-historische Classe, 15, 1-79.

Fauvelle-Aymar F.-X., Bruxelles L., Mensan R., Bosc-Tiesse C., Derat M.-L., Fritsch E., 2010, Phasing Lalibela (Ethiopia). Making sense out of a nonstratigraphic archaeological site, Antiquity, 84 (326), 1135-1150.

Fritsch E., 2008, The Churches of Lalibäla (Ethiopia) Witnesses of Liturgical Changes, Bollettino della Badia Greca di Grottaferrata, 5, 69-112.

Gervers M., 2003, The rehabilitation of the Zaguë kings and the building of the Däbrä Sina-Golgotha-Sellassie complex in Lalibäla, Africana Bulletin, 51, 23-49.

Godet E., 1988, Tableaux chronologiques relatifs à la fin de l'époque axoumite et à la période des Zagwés, Proceedings of the Nineth International Congress of Ethiopian Studies, Moscou, 1988, 6, 22-57.

Habtemichael Kidane \& Red., 2005, Gäbäz, in Encyclopaedia Aethiopica ${ }_{2}$ Uhlig S. ed., Wiesbaden, 2, 599-600.

Henze P., 2007, Church and monastery treasures of Tigray (private), in Orbis Aethiopicus, Beiträge zu Geschichte, Religion und Kunst Äthiopiens band X, Raunig W. \& Asfa-Wossen Asserate ed., Lublin (Bibliotheca nubica et æthiopica, 10), 149-159. 


\section{Marie-Laure Derat}

Khater A., Burmester O.H.E., 1968, History of the Patriarchs of the Egyptian church, known as the History of the Holy Church by Sawirus ibn al-Mukaffa, Bishop of alAsmunin, Le Caire.

Khater A., Burmester O.H.E., 1970, History of the Patriarchs of the Egyptian church, known as the History of the Holy Church by Sawirus ibn al-Mukaffa, Bishop of alAsmunin, Le Caire.

Kropp M., 1992, Siegbert UHLIG: Äthiopische Paläographie. Stuttgart, 1988 (Aethiopistische Forschungen. 22.) Mit einem Exkurs: Die Datierung der Hs. Abba Garima II., Oriens Christianus, 76, 260-266.

Kropp M., 1994, Der siegreiche Feldzug des Königs Amda Seyon gegen die Muslime in Adal im Jahre 1332 N. Chr., Louvain (CSCO 538-539, Script. Aeth. 99-100).

Kropp M., 2005, “Antiquae testitutio legis”. Zur Alimentation des Hofklerus und einer Zeugenliste als imago imperii und notitia dignitatum in einer Urkunde des Kaisers Zär'a Ya'qob im condaghe der Hs. BM Or. 481, fol. 154, Scrinium, 1, 115 147.

Kur S., Derat M.-L., 2007, Mäsqäl Kəbra, in Encyclopaedia Aethiopica ${ }_{2}$ Uhlig S. ed., Wiesbaden, 3, 844-845.

Ludolf J., 1698-1699, Lexicon aethiopico-latinum, Frankfurt.

Marrassini P., 1993, Lo scettro e la croce, la campagna di Amda Seyon I contro l'Ifat (1332), Napoli (Studi africanisti, serie etiopica 4).

Marrassini P., 1995, Il Gädlä Yemreḥanna Krestos. Introduzione, testo critico, traduzione, Napoli (Supplément au n85 des Annali del Istituto Universitario Orientale).

Monti della Corte A.A., 1940, Lalibelà. Le chiese ipogee e monolitiche e gli altri monumenti medievali del Lāstā, Roma.

Mordini A., 1961, La chiesa di Baraknaha, nello Scimezana, Annales d'Éthiopie, 4, 131-138.

Pankhurst R., 1977, The History of Bareya, Sanqella and Other Ethiopian Slaves from the Borderlands of the Sudan, Sudan Notes and Records, 58, 1-43.

Perruchon J., 1892, Vie de Lalibäla, roi d'Éthiopie, Paris.

Perruchon J., 1893, Les chroniques de Zar'a Ya'qôb et de Ba'eda Mâryâm, rois d'Éthiopie de 1434 à 1478, Paris.

Perruchon J., 1898-1899, Notes pour l'histoire d'Éthiopie. Extrait de la vie d'abba Jean, $74^{\mathrm{e}}$ patriarche d'Alexandrie, relatif à l'Abyssinie (texte arabe et traduction), Revue Sémitique, 6, p. 267-271; 7, 76-88.

Phillipson D., 2009, Ancient Churches of Ethiopia. Fourth-Fourteenth Centuries, Yale University Press.

Schneider M., 1970, Deux actes de donation en arabe, Annales d'Éthiopie, 8, 79-84.

Schneider R., 1989, L'évangéliaire de Dabra Libanos de Ham, in Proceedings of the Eighth International Conference of Ethiopian Studies, Taddesse Beyene ed., Addis Ababa, 2, 163. 
Sciarrino J.-F., 1994, Le "Ser'ata Q" erbat". Recherches sur le cérémonial éthiopien du sacre des rois avant le XVI siècle, Mémoire de maîtrise d'histoire, Université Paris-I.

Sokolinskaia E., 2007, Liq, in Encyclopaedia Aethiopica, Uhlig S. ed., Wiesbaden, 3, 576578.

Taddesse Tamrat, 1972, Church and State in Ethiopia, 1270-1527, Oxford.

Uhlig S., 1988, Äthiopische Paläographie, Stuttgart (Aethiopistische Forschungen, 22).

Uhlig S., 1990, Introduction to Ethiopian Paleography, Stuttgart (Aethiopistische Forschungen, 28).

\section{Résumé / Abstract}

Derat M.-L., 2010, Les donations du roi Lālibalā : éléments pour une géographie du royaume chrétien d'Éthiopie au tournant du XIIII siècle, Annales d'Éthiopie, 25, 19-42.

La documentation écrite concernant le roi Lālibalā, contemporaine de son règne et produite dans le royaume d'Éthiopie, consiste en trois donations de terre, fort peu étudiées jusqu'ici : la donation inscrite dans l'évangéliaire conservé à Bēta Medhānē 'Alam à Lālibalā et les deux chartes de "l'Évangile d'or » de Dabra Libānos du Šemazānā. Le propos de cet article est de donner une nouvelle édition de ces textes, accompagnées d'une traduction. Cela est possible suite à l'apport considérable des photographies de cet Évangile réalisées par Roger Schneider et conservées aujourd'hui dans une dépendance de l'Institute of Ethiopian Studies, le centre Walda Masqal à Addis Ababa, qui conserve les archives Roger Schneider. Puis une discussion sera ouverte concernant les informations géographiques transmises par ces textes, afin de considérer d'un œil neuf la question de la gestion du territoire du royaume par le roi zāg ${ }^{w} \bar{e}$, l'extension de celui-ci et son centre.

Mots-clefs: royaume chrétien d'Éthiopie, Lālibalā, Begwenā, dynastie Zāgwēē, donations de terre.

The donations of King Lālibalā: elements for a geography of the Ethiopian Christian Kingdom at the turn of the $13^{\text {th }}$ centuries - The written documentation on king Lālibalā, produced in the kingdom of Ethiopia when this king was reigning, is composed of three land grants, up to now objects of little scientific interest: the land donation recorded in the gospel preserved in Bēta Medhānē 'Alam (Lālibalā) and the two charters of the "Golden Gospel" of Dabra Libānos of Šemazānā. The purpose of this article is to give a new edition of these three texts, with a translation. This work is based on the study of the photographs of the Dabra Libānos gospels taken by Roger Schneider and now available in the Walda Masqal Centre, a department of the Institute of Ethiopian Studies, which preserves the archives of Roger Schneider. The geographical information transmitted by those texts will then be discussed in order to 


\section{Marie-Laure Derat}

sort out the questions of the kingdom's territory and its management, its extension and its centre.

Keywords: Ethiopian Christian kingdom, Lālibalā, Begwenā, Zāgwē dynasty, land grants. 